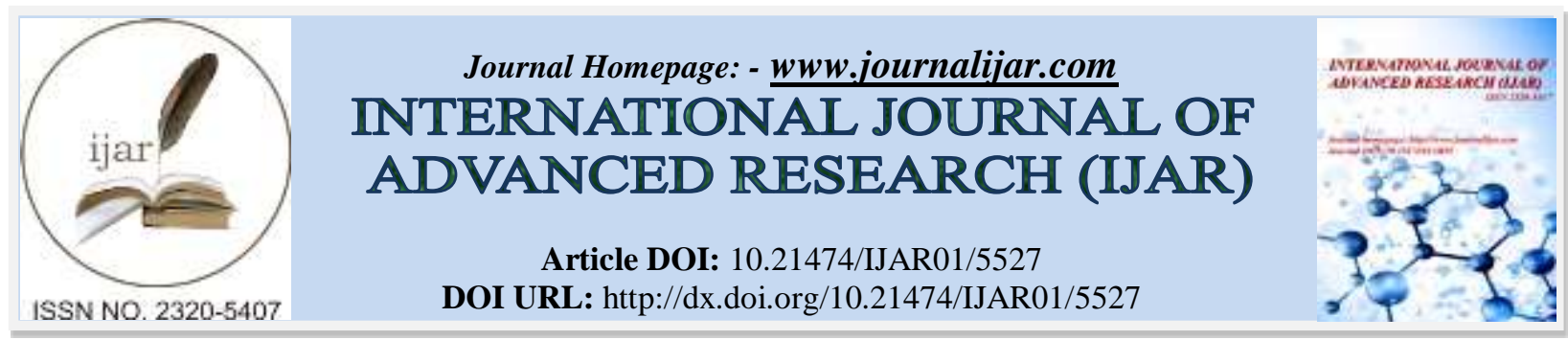

RESEARCH ARTICLE

\title{
PERFORMANCE CHARACTERISTICS OF DIVERGENCE MICRO-CHANNELS HEAT SINK USING NANOFLUIDS.
}

\author{
Sana J. Yaseen ${ }^{1}$, Abdul Muhsin A. Rageb ${ }^{2}$ and Ahmed K. Alshara ${ }^{3}$. \\ 1. Mechanical Engineering Department, Basrah University, Basrah, Iraq. \\ 2. Mechanical Engineering Department, Basrah University, Basrah, Iraq. \\ 3. Civil Engineering Department, MisanUniversity, Misan, Iraq.
}

\section{Manuscript Info}

Manuscript History

Received: 03 August 2017

Final Accepted: 05 September 2017

Published: October 2017

Key words:-

heat transfer, divergence micro channel,

heat sink, nanofluids, pressure drop.

\begin{abstract}
In the present study, fluid flow and heat transfer in microchannel heat sinks with divergence microchannels using two nanofluids were numerically studied including the entire microchannel heat sink. The divergent channel has the cross-section of $100 \times 100 \mu \mathrm{m}^{2}$ at inlet and $560 \times 100 \mu \mathrm{m}^{2}$ at exit. The pressure drop and thermal characteristics of heat sinks were investigated for Reynolds number varying from 50 to 250 and at constant heat flux. The effect of Reynolds number on Nusslet number and on pressure drop was studied. The results show that the volume fraction of nanoparticles and Reynolds number has major effect on microchannels heat transfer enhancement.
\end{abstract}

Copy Right, IJAR, 2017,. All rights reserved.

\section{Introduction:-}

Throughout the last 20 years, the frontier of microfluidics has expanded rapidly. It has been shown that heat sinks with minor channel dimensions has many industrial applications such as automotive and aerospace microchannel heat exchangers, cooling of high power electronic devices pumps [1], heat transfer for microelectronics cooling, condensation heat transfer, chemical reactions in microfluidic devices [2]. Also, the customer demands of lower prize and greater reliability are forcing rapid market modifications and enhanced product developments. Due to these enhancements in micro channels, the heat fluxes have increased extremely and expected to fast go beyond 100 $\mathrm{W} / \mathrm{cm}^{2}$ [3].

The major disadvantage of electronic systems was the temperature rise. The performance of electronic system decays suddenly when the temperature of the electronic devices rises away from a certain threshold limit. Large fluctuations of temperature become responsible for the service life of the electronic equipment [4].

Using water as a cooling fluid has some disadvantage in microchannels, as the narrow operating temperature range and lower thermal conductivity. There are many ideas for improving cooling technology for electronic equipment that produced high heat generation; one of these methods was using Nanofluids. Nanofluids is a new type of heat transfer medium having a nanoparticle $(1-100 \mathrm{~nm})$ that are distributed in uniform and constant form in a base fluid. This new coolant method gives a novel direction for very high cooling performance by combination of a microchannels heat sink with nanofluids [5]. The word 'nanofluid' denotes to a two-phase mixture collected of a liquid phase and discrete nanoparticles in suspension. Thus nanofluids could be a promising replacement for pure water in microchannel where there is need to more efficient heat transfer and further improving in performance of the liquid-cooled microchannel heat sinks [6]. 
Microchannel heat sink was first proposed in the 1980's by Tuckerman and Pease (1981) [7] for electronic cooling. They used silicon micro channels, with water as the working fluid, to dissipate power from an electronic chip. These channels capable to dissipated up to $790 \mathrm{~W} / \mathrm{cm}^{2}$ while maintaining a chip temperature below $110^{\circ} \mathrm{C}$.

Microchannel heat sink studied by Duangthongsuk and Wongwises (2011) [8] experimentally using $\mathrm{Al}_{2} \mathrm{O}$-water nanofluids. They studied Reynolds number effects and particle concentrations on thermal and fluid characteristics. The particle concentrations were of 1,2 and $3 \%$ of $\mathrm{Al}_{2} \mathrm{O}$-water nanofluids, with total power of $100 \mathrm{~W}$. Their results showed that the heat transfer values of nanofluid were greater than base fluid by about $7-15 \%$.

The thermal and fluid characteristics for square microchannel heat sink studied by Manay et al. (2012) [9] numerically. The working fluid was water as a based and nanofluids of $\mathrm{Al}_{2} \mathrm{O}$ and $\mathrm{CuO}$ particles with four volume fractions of $0 \%, 0.5 \%, 1 \%, 1.5 \%$ and $2 \%$. They assumed single phase of flow with uniform dispersals of the particles in water. The calculations give the values of Nusselt number and the pressure drop. Their results show that when Reynolds number and the volume fractions increased the heat transfer improved. Also they noticed that the greatest global improvement was attained at volume fraction for $\mathrm{CuO}$-water nanofluid of $\% 2$ at Reynolds number of 100.

The thermal and fluid characteristics of microchannels investigated numerically by Sheikhzadeh et al. (2013) [6] using $\mathrm{Al}_{2} \mathrm{O}$-water nanofluid as a coolant. Different volume fractions of nanoparticles and various Reynolds numbers are used in this study. Their results composed calculation of Nusselt number, thermal resistance, pressure drop and temperature along the microchannels. They concluded that using nanofluid increased thermal augmentation with small increased in pressure drop, and increasing Reynolds number resulted in rise pressure drop and reduced thermal resistance.

Khaeffef (2014) [10] studied The thermal and fluid characteristics of rectangular microchannels heat sink using nanofluids as coolant numerically. He used Reynolds number in the range of 100 to 400 with heat flux of 50,100 and $150 \mathrm{~W} / \mathrm{cm}^{2}$. He used $\mathrm{Al}_{2} \mathrm{O}_{3}$-water and cu-water as nanofluids with volume concentrations of $10 \%$. He concluded that when Reynolds number increased, pressure drop and heat transfer also increased while friction factor reduced. Also he noticed that enhancement in heat transfer using $\mathrm{Cu}$-water larger than using $\mathrm{Al}_{2} \mathrm{O}_{3}$-water.

Rectangular microchannel heat sink studied by Adham et al. (2016) [11] using nanofluid as working fluid. They used $\mathrm{SiC}-\mathrm{HO}$ and $\mathrm{TiO}_{2}-\mathrm{H}_{2} \mathrm{O}$ with particles concentrations of $1 \%, 3 \%, 5 \%, 7 \%$ and $9 \%$ to improved heat sink performance using thermal resistance method with genetic algorithm. They noticed that by increasing particles concentrations the thermal resistance reduced and driving power growth. They observed that SiC-HO consumed more driving power than $\mathrm{TiO}_{2}-\mathrm{H}_{2} \mathrm{O}$, also at the same operating conditions the nanofluids have low thermal resistance compared to water.

Ebrahimi (2016) [12] studied three dimensional rectangular miceochannels heat sink numerically at different Reynolds numbers. They used $\mathrm{Al}$ and $\mathrm{Cu}$ at different particles volumes from $0.5 \%$ to $3 \%$ for two nanofluids with water as base fluid. The improvement in heat transfer and increasing in pressure drop using water- $\mathrm{Al}_{2} \mathrm{O}$ and water$\mathrm{CuO}$ was $2.29-30.63 \%$ and $9.44 \%-53.06 \%, 3.49 \%-16.85 \%$ and $6.5 \%-17.70 \%$, also the total efficiency was enhanced by $2.55 \%-29.05 \%$ and $9.78 \%-50.64 \%$ for the two nanofluids respectively.

The objective of the present work is to investigate the thermal and hydrodynamics characteristics of nanofluids in heat sinks with divergence microcchannels. Thus, the present study deals with three dimensional numerical simulations of laminar nanofluids flow and heat transfer characteristics through $\mathrm{MCHS}_{\mathrm{s}} \mathrm{sing}$ two nanofluids $\mathrm{Al}_{2} \mathrm{O}$ and $\mathrm{TiO}_{2}$ with nanoparticle volume fraction of $(1,3,5,7) \%$. The Reynolds number is the range of 50-250, and the heat flux is fixed at $90 \mathrm{~W} / \mathrm{cm}^{2}$. Results of interests such as temperature distribution, Nusselt number and effect of Reynolds number on Nusselt number were reported in this paper.

\section{Mathmatical Model:-}

A schematic diagram of the heat sink is presented in figure 1. One column of channels consists of five divergence channels are taken to reduce the computational time as shown in Figure 1 (a). While Figure 1 (b) represents details of one divergence channel. The heat sink is made from silicon and two nanofluid is used as the cooling fluid. 


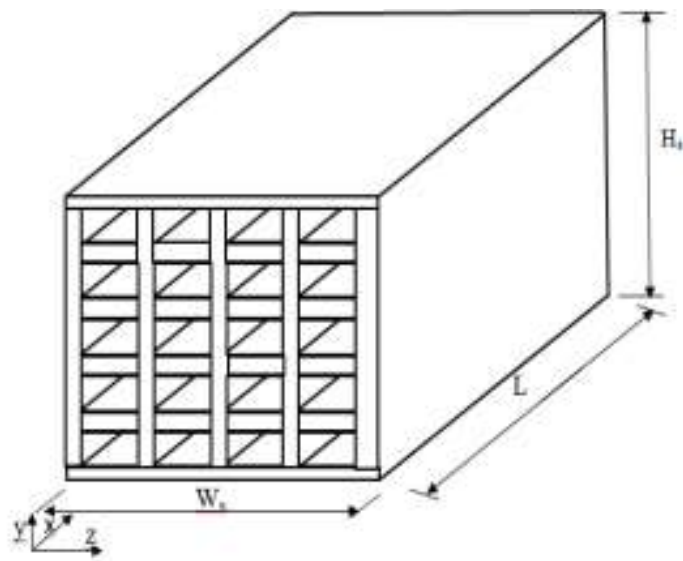

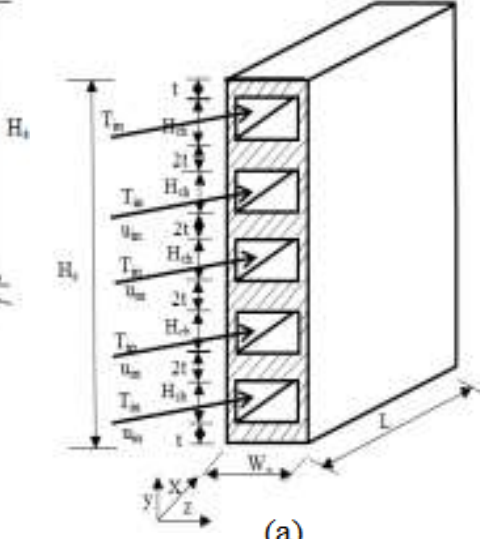

(a)

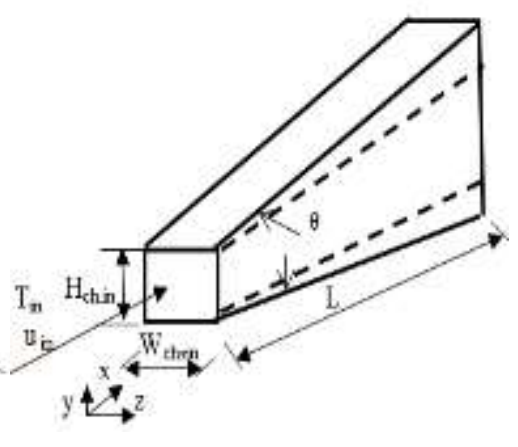

(b)

Figure 1:- schematic model for the whole heat sink

(a) Schematic of heat sink column (five channels) (b) one divergence channel

\section{Governing equations:-}

The problem under consideration concerns the flow through heat sink contains different microchannels. Heat transfer in the heat sink unit is a conjugate process combining heat conduction in the solid wall and convection in the working fluids.

To investigate the thermal and flow characteristics of these models, the following assumptions are prepared

(1) Three-dimensional, incompressible, laminar and steady state flow is assumed.

(2) No slip flow is supposed.

(3) The energy dissipation is negligible.

(4) Radiation heat transfer is negligible.

(5) Gravity effect is negligible.

(6) Constant liquid and solid properties are assumed.

The system of equations for 3D based on the previous assumptions, governs the single phase model equations include the continuity, momentum and energy equations, can be written as follows [13]:

Continuity equation

$$
\frac{\partial u}{\partial x}+\frac{\partial v}{\partial y}+\frac{\partial w}{\partial z}=0
$$

Momentum equations in $\mathrm{x}, \mathrm{y}$ and $\mathrm{z}$ directions (Navier stokes equations) can be written as [13]:

$u \frac{\partial u}{\partial x}+v \frac{\partial u}{\partial y}+w \frac{\partial u}{\partial z}=-\frac{1}{\rho} \frac{\partial P}{\partial x}+\frac{\mu}{\rho}\left(\frac{\partial^{2} u}{\partial x^{2}}+\frac{\partial^{2} u}{\partial y^{2}}+\frac{\partial^{2} u}{\partial z^{2}}\right)$

$u \frac{\partial v}{\partial x}+v \frac{\partial v}{\partial y}+w \frac{\partial v}{\partial z}=-\frac{1}{\rho} \frac{\partial P}{\partial y}+\frac{\mu}{\rho}\left(\frac{\partial^{2} v}{\partial x^{2}}+\frac{\partial^{2} v}{\partial y^{2}}+\frac{\partial^{2} v}{\partial z^{2}}\right)$

$u \frac{\partial w}{\partial x}+v \frac{\partial w}{\partial y}+w \frac{\partial w}{\partial z}=-\frac{1}{\rho} \frac{\partial P}{\partial z}+\frac{\mu}{\rho}\left(\frac{\partial^{2} w}{\partial x^{2}}+\frac{\partial^{2} w}{\partial y^{2}}+\frac{\partial^{2} w}{\partial z^{2}}\right)$

Energy equation for fluid and solid walls can be written in the following form respectively [14]:

$$
\begin{aligned}
& u \frac{\partial T}{\partial x}+v \frac{\partial T}{\partial y}+w \frac{\partial T}{\partial z}=\frac{k}{\rho C p}\left(\frac{\partial^{2} T}{\partial x^{2}}+\frac{\partial^{2} T}{\partial y^{2}}+\frac{\partial^{2} T}{\partial z^{2}}\right) \\
& \frac{\partial^{2} T_{s}}{\partial x^{2}}+\frac{\partial^{2} T_{s}}{\partial y^{2}}+\frac{\partial^{2} T_{s}}{\partial z^{2}}=0
\end{aligned}
$$

\section{The boundary conditions:-}

Based on the figure 1 and the previous assumptions, the following boundary conditions are applied to the computational domain in the present study:

1) For all channels (fluids) at $x=0 \quad$ (inlet) $u=u_{\text {in }}, v=w=0, T=T_{\text {in }}$

$$
\text { at } x=L \quad \text { (outlet) } \frac{\partial u}{\partial x}=\frac{\partial v}{\partial x}=\frac{\partial w}{\partial x}=0, \frac{\partial T_{f}}{\partial x}=0
$$


Solid-fluid interface $\quad u=v=w=0,-k_{f} \frac{\partial T_{f}}{\partial z}=-k_{s} \frac{\partial T_{s}}{\partial z}, T_{f}=T_{s}$

2) Solid wall (heat sink) all the walls adiabatic except the top sink where

$$
\overline{\bar{q}}=\text { constant }=-k_{s} \frac{\partial T_{s}}{\partial T_{y}}
$$

\section{Method of Solution:-}

The heat sink under consideration has a $0.24,3.5$ and $26 \mathrm{~mm}$ width, height and length respectively. It contains microchannel with a square cross section of $100 \mu \mathrm{m} \times 100 \mu \mathrm{m}$ at inlet and divergent with angle $0.5^{\circ}$ along the channel length of $26 \mathrm{~mm}$. The calculations made firstly using water as a base fluid then repeated with two nanofluids with different nanoparticles volume concentration. The solid particles are titanium dioxide $\left(\mathrm{TiO}_{2}\right)$ for the first nanofluid and Aluminum oxide $\left(\mathrm{AL}_{2} \mathrm{O}_{3}\right)$ for the second which dissolved in water. The volume fractions used are $(1 \%, 3 \%, 5$ $\%$, and $7 \%$ ) for each nanofluid.

The nanofluid enters the channel with a uniform velocity and temperature. Constant heat flux $\left(90 \mathrm{~W} / \mathrm{cm}^{2}\right)$ was supplied on the upper wall of the heat sink. The other wall assumes adiabatic. The thermo-physical properties were assumed to be temperature independent and, the flow was steady state.

Thermo physical properties of the nanofluids such as density, viscosity and thermal conductivity are consider the significant parameters for calculating the heat transfer performance; they are usually expressed in nanoparticle volume fraction $\varphi$. The nano properties (the density, specific heat, viscosity and thermal conductivity) that required for flow were calculated using the following equations [11]:

The density:

$$
\rho_{\text {eff }}=(1-\varphi) \rho_{f}+\varphi \rho_{p}
$$

Specific heat:

$$
\left(\rho C_{p}\right)_{e f f}=(1-\varphi)\left(\rho C_{p}\right)_{f}+\varphi\left(\rho C_{p}\right)_{p}
$$

Viscosity:

$$
\mu_{e f f}=\frac{\mu_{f}}{(1-\varphi)^{2.5}}
$$

Thermal conductivity:

$$
k_{e f f}=k_{f}\left[\frac{\left(k_{p}+2 k_{f}\right)-2 \varphi\left(k_{f}-k_{p}\right)}{\left(k_{p}+2 k_{f}\right)+\varphi\left(k_{f}-k_{p}\right)}\right]
$$

where $\mathrm{C}_{\mathrm{pf}}, \mathrm{C}_{\mathrm{pp}}, \mathrm{C}_{\mathrm{peff}}, \mu_{\mathrm{f}}, \mu_{\mathrm{eff}}, \rho_{\mathrm{f}}, \rho_{\mathrm{p}}, \rho_{\mathrm{eff}}, \mathrm{k}_{\mathrm{f}}, \mathrm{k}_{\mathrm{p}}$ and $\mathrm{k}_{\mathrm{eff}}$ specific heats of base fluid, nanoparticles, effective specific heat of nanofluids, viscosity of base fluid, effective viscosity of nanofluids, density of base fluid, nanoparticles, the

\begin{tabular}{|c|c|c|c|c|c|}
\hline properties & \multicolumn{5}{|l|}{$\mathrm{TiO} 2$} \\
\hline$\varphi$ & $0 \%$ & $1 \%$ & $3 \%$ & $5 \%$ & $7 \%$ \\
\hline$\rho_{n f}\left(\mathrm{kgm}^{-3}\right)$ & 4175 & 1029.788 & 1092.964 & 1156.14 & 1219.316 \\
\hline$\mu_{\mathrm{nf}}\left(\mathrm{Ns}^{-1} \mathrm{~m}^{-2}\right)$ & ------ & 0.001029 & 0.001082 & 0.00114029 & 0.001203 \\
\hline $\mathrm{C}_{\mathrm{pnf}}\left(\mathrm{Jkg}^{-1} \mathrm{~K}^{-1}\right)$ & 4157 & 4041.844 & 3785.836 & 3557.806 & 3353.407 \\
\hline $\mathrm{K}_{\mathrm{nf}}\left(\mathrm{Wm}^{-1} \mathrm{~K}^{-1}\right)$ & 8.4 & 0.62494 & 0.65556 & 0.68722 & 0.719965 \\
\hline properties & & $\mathrm{Al}_{2} \mathrm{O}_{3}$ & & & \\
\hline$\varphi$ & $0 \%$ & $1 \%$ & $3 \%$ & $5 \%$ & $7 \%$ \\
\hline$\rho_{n f}\left(\mathrm{kgm}^{-3}\right)$ & 3970 & 1027.918 & 1087.354 & 1146.79 & 1206.226 \\
\hline$\mu_{\mathrm{nf}}\left(\mathrm{Ns}^{-1} \mathrm{~m}^{-2}\right)$ & ------ & 0.001029 & 0.00108 & 0.00114 & 0.001203 \\
\hline $\mathrm{C}_{\mathrm{pnf}}\left(\mathrm{Jkg}^{-1} \mathrm{~K}^{-1}\right)$ & 765 & 4026.177 & 3740.084 & 3483.646 & 3252.479 \\
\hline $\mathrm{K}_{\mathrm{nf}}\left(\mathrm{Wm}^{-1} \mathrm{~K}^{-1}\right)$ & 40 & 0.627656 & 0.664011 & 0.70182 & 0.741188 \\
\hline
\end{tabular}
effective density of nanofluids, thermal conductivity of base fluid, nanoparticles, effective thermal conductivity of nanofluids respectively.

The thermo-physical properties of nanoparticles can be shown in table I.

Table I:- Thermo- physical properties of nanofluids

In the present study the nanofluid is treated as a single-phase fluid due to very small particles taken, this assumption can be appropriate due to tiny size of the particles and it fluidized simply in water. Under such assumption the fluid flow and heat transfer governing equations are simplified since the base fluid and particles are assumed in thermal equilibrium and move with the similar velocity. 


\section{Model validation:-}

The grid dependence test was done using several different mesh sizes for better result accuracy. Commercial mesh generator software, ICEM CFD, is used to generate the numerical domain and a CFD solver and Fluent, is used for the simulation of laminar flow.

Four mesh sizes were used and the governing equations were solved based on these four meshes respectively. First mesh size is $(60 \times 162 \times 10)$, the second mesh size is $(70 \times 182 \times 15)$, the third is $(80 \times 212 \times 20)$ and the fourth is $(90 \times 262 \times 25)$ in $\mathrm{z}, \mathrm{y}, \mathrm{x}$ directions respectively.

The results obtained from these meshes at $\mathrm{Re}=50$ are summarized in table II bellows which shows the number of nodes and number of elements used and fluid temperature at $\mathrm{x}=5 \mathrm{~mm}$ from channel inlet region.

Table II:- Grid Independency Check

\begin{tabular}{|l|l|l|}
\hline Serial No. & No. of nodes & bulk Temperature(K) \\
\hline 1 & $60 \times 162 \times 10$ & 304.78101 \\
\hline 2 & $70 \times 182 \times 15$ & 304.7844 \\
\hline 3 & $80 \times 212 \times 20$ & 304.78609 \\
\hline 4 & $90 \times 262 \times 35$ & 304.8099 \\
\hline
\end{tabular}

From these results it can be seen that the solution becomes independent of grid at third grid type and increasing the size of mesh more than the third one do not have a significant effect on the results.

To check the accuracy of present numerical model with nanofluids- as a cooling fluid, validation is made by comparing the numerical results of present model with that of Noh and Sidik reference [15]. The model presented in [15] consists of a micro-heat sink of dimensions $57 \mu \mathrm{m} \times 180 \mu \mathrm{m} \times 10 \mathrm{~mm}$ width, depth and length respectively, with a single rectangular channel of dimension $(900 \mu \mathrm{mx} 100 \mu \mathrm{mx} 10 \mathrm{~mm})$. Thermal boundary condition was a constant heat flux of $90 \mathrm{~W} / \mathrm{cm}^{2}$ acting at the top wall of heat sink.

Figure 2 represents a distribution temperature on the top wall of the channel using the present model and numerical results of ref. [15] with diamond - water as a coolant fluid. From these curves it can be noted that, the agreement between results of present model and results of [15] is accepted since the mean error $0.69 \%$. From these results it can be observable that, the present model can be carefully used to simulate a MCHS with nanofluids as a cooling fluid.

\section{Results and discussion:- Nusselt Number:-}

The influences of various volume fractions of the nanoparticles on the average Nusselt number on channel 1 walls are presented in figures 3 and 4 for $\mathrm{TiO}_{2}$-water and $\mathrm{Al}_{2} \mathrm{O}_{3}$-water respectively. It is clear that the Nusselt number of nanofluid is higher than that of the base fluid as the presence of nanoparticles and Nusselt number increases with the volume concentration of it. This behavior belongs to the increases in the thermal conductivity of the nanofluid, as the concentration of nanofluid increases, which are the favorite factors for heat transfer enhancement. In concentration range studied (1-7\%), the effect of the increase in thermal conductivity and the collision of nanoparticles are more noticeable than the increase of the fluid viscosity $\left(\mathrm{K}_{\mathrm{f}}\right.$ increases by $20 \%$ and $24 \%$ while $\mu_{\mathrm{f}}$ increases by 19\%) for two nanofluid respectively. These figures show that the addition of nanoparticles to base fluid results in enhancement of heat transfer, because of the distribution and random movement of nanoparticles inside the fluid.

Figure 5 indicate Nusslet number along channel 1 for $\mathrm{TiO}_{2}$-water and $\mathrm{Al}_{2} \mathrm{O}_{3}$-water nanofluids at different volume concentrations. By looking at these figures, it can identify that $\mathrm{Al}_{2} \mathrm{O}_{3}$-water gives higher value of $\mathrm{Nu}$ at the same volume concentrations compared of $\mathrm{TiO}_{2}$-water. This belongs to higher thermal conductivity of $\mathrm{Al}_{2} \mathrm{O}_{3}$ - $\mathrm{water}$ as compared to $\mathrm{TiO}_{2}$-water at the same volume concentrations. Increases of $31.86 \%$ and $27.14 \%$ of $\mathrm{Nu}$ can be found when using $7 \%$ volume concentrations of both $\mathrm{Al}_{2} \mathrm{O}_{3}$ and $\mathrm{TiO}_{2}$ respectively.

Average Nusselt number on channels walls are presented in figures 6 and 7 for $\mathrm{TiO}_{2}$-water and $\mathrm{Al}_{2} \mathrm{O}_{3}$-water respectively. These figures show the variation of $\mathrm{Nu}$ with various volume concentrations of nanoparticles. It is obvious that the Nusselt number increases with volume concentrations of nanofluids. At the same time it appears 
that the upper channel (channel 1) has the higher value of $\mathrm{Nu}$ followed by channel $2, \ldots$ etc, this occurred owing to the channel location on the upper of the rest channels and near the heat flux applied from the top sink.

\section{Pressure drop:-}

Another important parameter in the MCHS operation is the pressure drop. The pressure drop is related to the pumping power required for driving the fluid flowing through the MCHS.

Figures 8 and 9 represent the relation between pressure drop and nanofluid concentration. From these figures it can observed that there is small difference between the pressure drop for both pure water and nanofluids when small volume concentration of nano particles is used. But when the concentrations of nanofluid increases higher pressure drop obtains compare with base fluid, this is due to increases the intensity of working fluid with volume concentration and the fluid becomes more viscous at higher volume fractions.

When compares these figures, it's clear that the pressure drop for $\mathrm{Al}_{2} \mathrm{O}_{3}$-water is larger than that for $\mathrm{TiO}_{2}$-water, this belongs to the difference of density and viscosity for two fluids appears in table I.

Figures 10 and 11 represent $\mathrm{Nu} / \Delta \mathrm{P}$ variation with volume concentrations for $\mathrm{TiO}_{2}$ and $\mathrm{Al}_{2} \mathrm{O}_{3}$ for five channels. It can observe that $\mathrm{Nu} / \Delta \mathrm{P}$ reduced with increasing $\varphi$, this is belonging to the increasing of the pressure drop with increasing volume partials of nanofluids. The pressure drop of $\mathrm{Al}_{2} \mathrm{O}_{3}$ was larger than that to $\mathrm{TiO}_{2}$ at the same volume concentration so $\mathrm{Nu} / \Delta \mathrm{P}$ for $\mathrm{TiO}_{2}$ was better than that for $\mathrm{Al}_{2} \mathrm{O}_{3}$.

\section{Effect of Reynolds number:-}

In order to show the Effect of Reynolds number on nanofluids, one of five channels is choose, it's the middle one and the thermal behavior of nanofluids at $\mathrm{Re}$ range (from 50 to 250) is drawn on $\mathrm{TiO}_{2}$-water with volume concentrations of $3 \%$.

$\mathrm{Nu}$ variation along the channel length at different Re was shown in figure 12. From this figure it is clear that when $\mathrm{Re}$ increases, $\mathrm{Nu}$ also increase and the maximum increased of $\mathrm{Nu}$ obtain at the entrance region since beyond this region fluid become fully developed, $\mathrm{Nu}$ has been found to increase as much as $26 \%$ compared to that of the base fluid when using $7 \%$ nanoparticles concentration. When velocity increase more particles cooperate of heat transfer through channel and increasing the concentration of the nanoparticles strengthens the mechanisms responsible for the enhanced heat transfer. Moreover, at high Re (flow rates), the disordered movement of the nanoparticles increased the mixing fluctuations and caused an increase in the heat-transfer coefficient

Figure 13 show the wall temperature variation along the upper channel at $\mathrm{TiO}_{2}$-water $3 \%$ volume concentrations, it was clear that when Re increase the average wall temperature reduced. The average wall temperature growth reduced when Reynolds number increased because a greater mass of fluid was available to transport the equivalent quantity of heat. So in order to obtain good temperature distribution along the channels walls it was preferred to increase Reynolds number.

At the same time figure 14 represent average fluid bulk temperature variations along the upper channel at $\mathrm{TiO}_{2}$ water 3\% volume concentration. Fluid temperature has the same behavior as the wall temperature it decreases when Re increases, a reduction of $15.17 \%$ of fluid temperature occurred when using nanofluids.

Figure 15 represent variation of $\mathrm{Nu}$ with $\mathrm{Re}$ along five channels at $\mathrm{TiO}_{2} 3 \%$. From this figure as $\mathrm{Re}$ increase $\mathrm{Nu}$ also increase due to increase of heat transfer. Also this figure show that channel 1 has large Nu value than other channels this belong to its location near the upper surface of heat sink where the heat flux applied.

The Heat Transfer Enhancement performance of heat sink (HTEP) which represented by $\left(\frac{(N u / \Delta P)_{\varnothing}}{\left({ }^{N u} / \Delta P\right)_{\text {water }}}\right.$ for five channels at different nano particles volume concentrations can be seen in table III. From this table it can be seen that as $\varphi$ increased the HTEP reduced; this belongs to increase the pressure drop with increase $\varphi$. From table III it can be seen that at the same nano particles volume concentration the HTEP for $\mathrm{TiO}_{2}$-water was larger than that for $\mathrm{Al}_{2} \mathrm{O}_{3^{-}}$ water. 


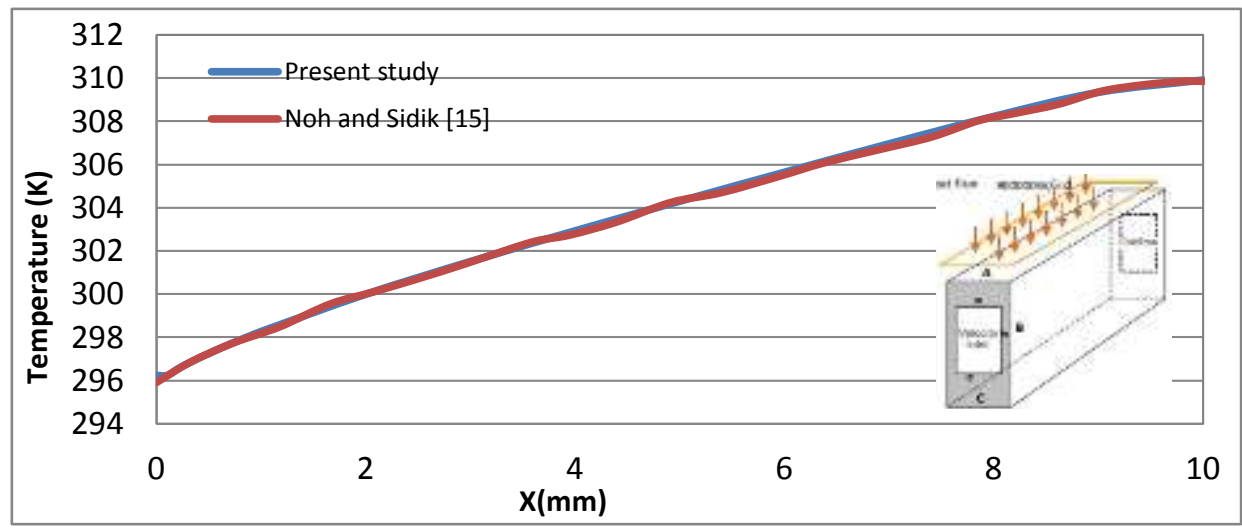

Figure 2: Temperature on the top wall of channel validation with ref.[14]

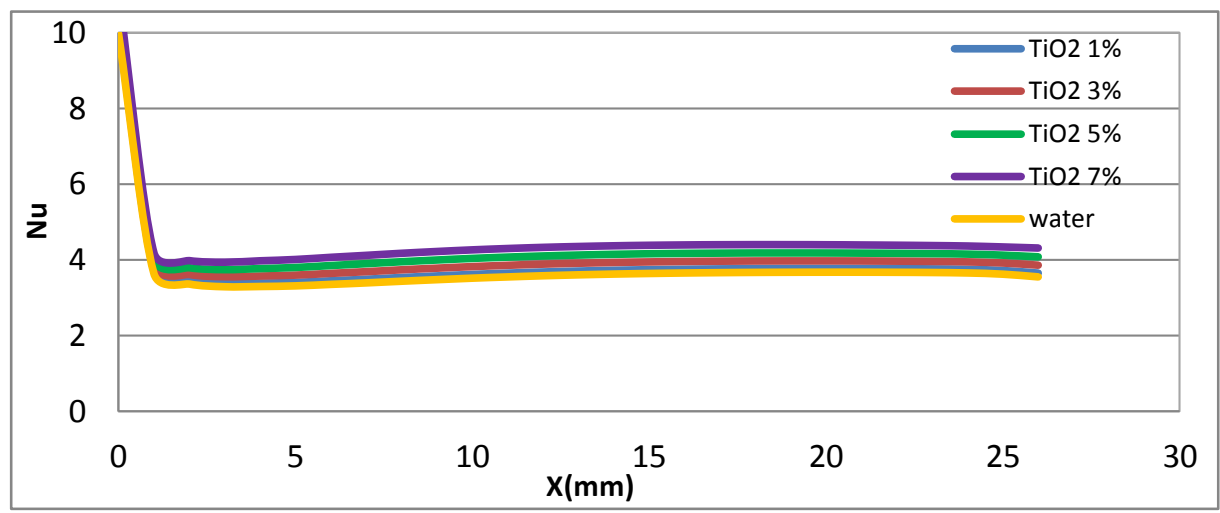

Figure 3:- $\mathrm{Nu}$ along axial distance at different volume from $\mathrm{TiO}_{2}$-water for channel1

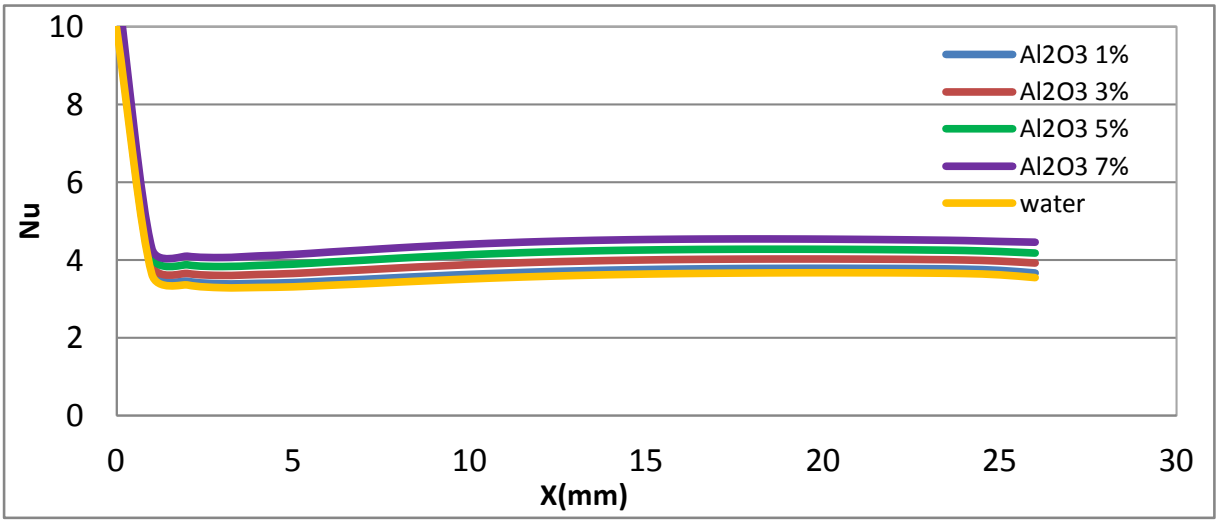

Figure 4: $\mathrm{Nu}$ along axial distance at different volume from $\mathrm{Al}_{2} \mathrm{O}_{3}$-water for

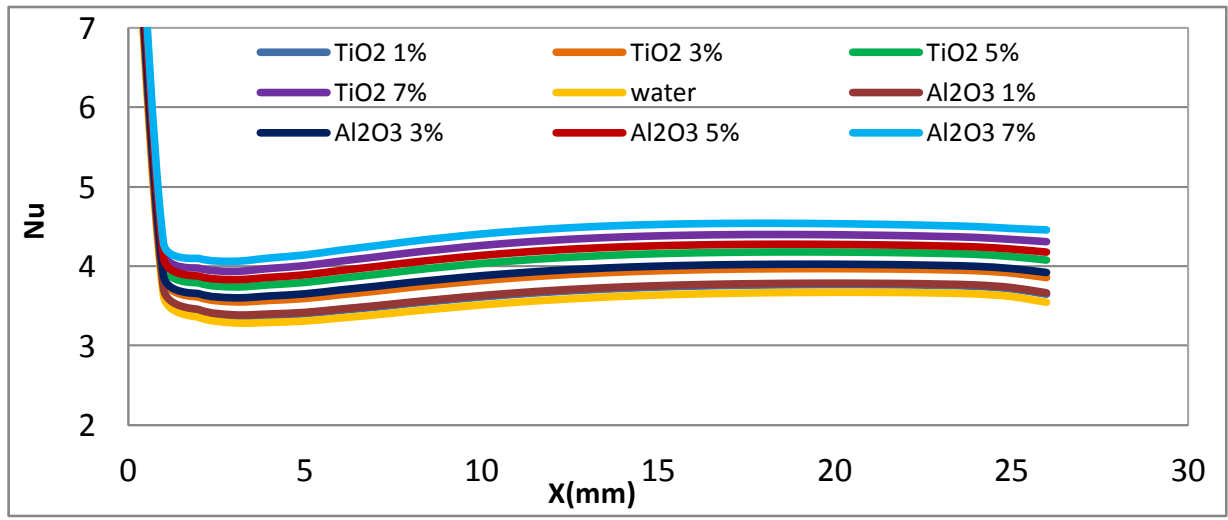

Figure 5: $\mathrm{Nu}$ along axial distance at different volume (two nanofluids for channel1) 


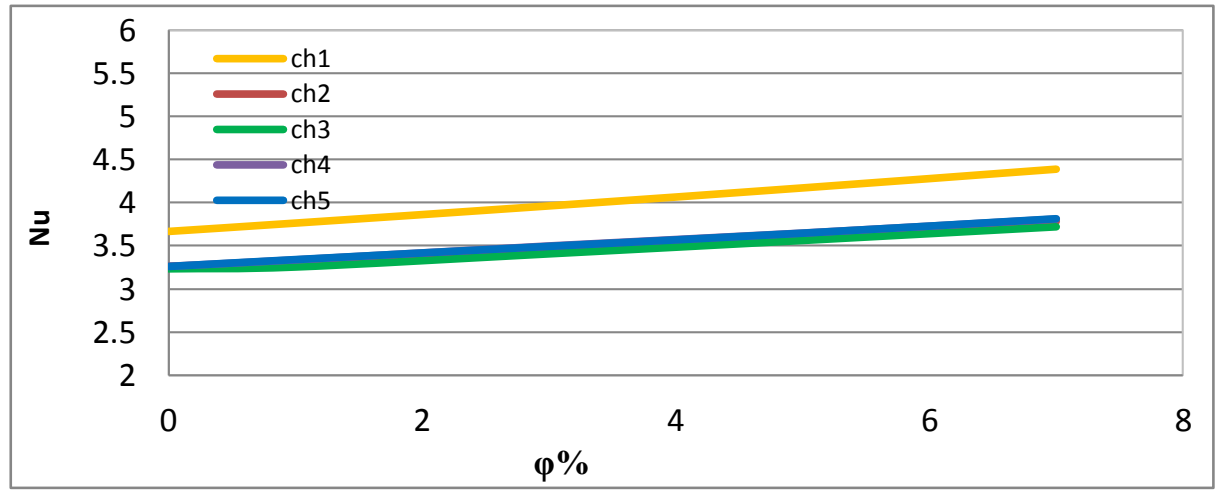

Figure 6: $\mathrm{Nu}$ variation verses volume concentration along five channels using $\mathrm{TiO}_{2^{-}}$ water

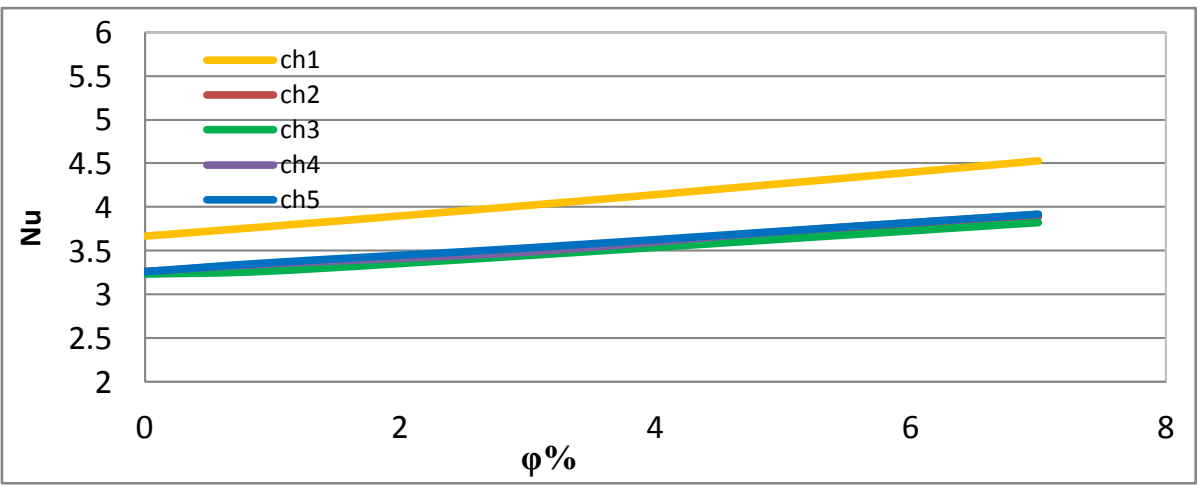

Figure 7: Nu variation with nano volume concentration along five channels using $\mathrm{Al}_{2} \mathrm{O}_{3}$-water

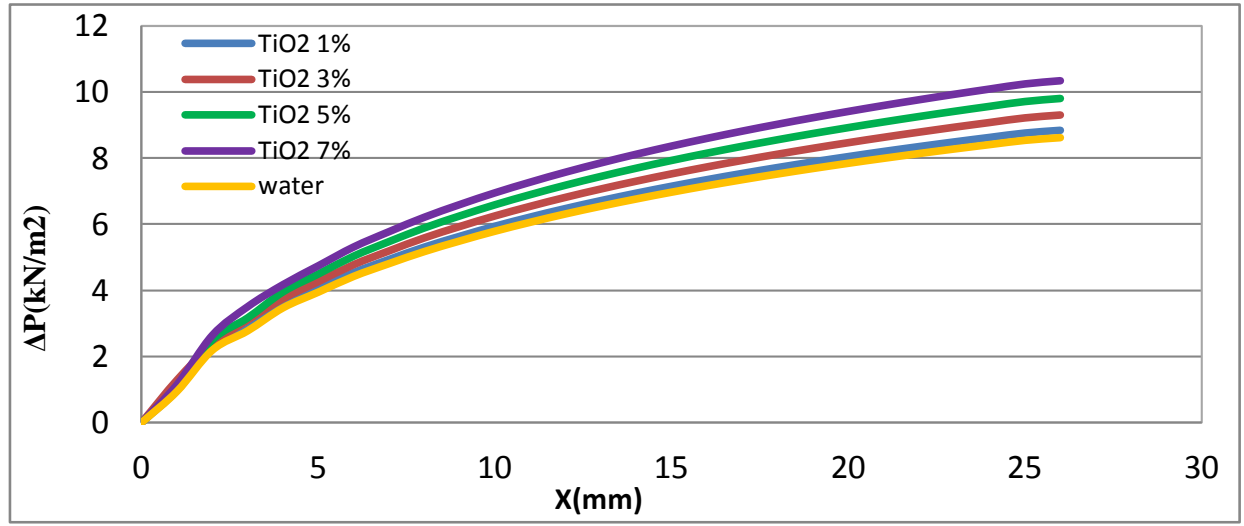

Figure 8: pressure drop along axial distance for $\mathrm{TiO}_{2}$-water for channell $(\mathrm{Re}=50)$

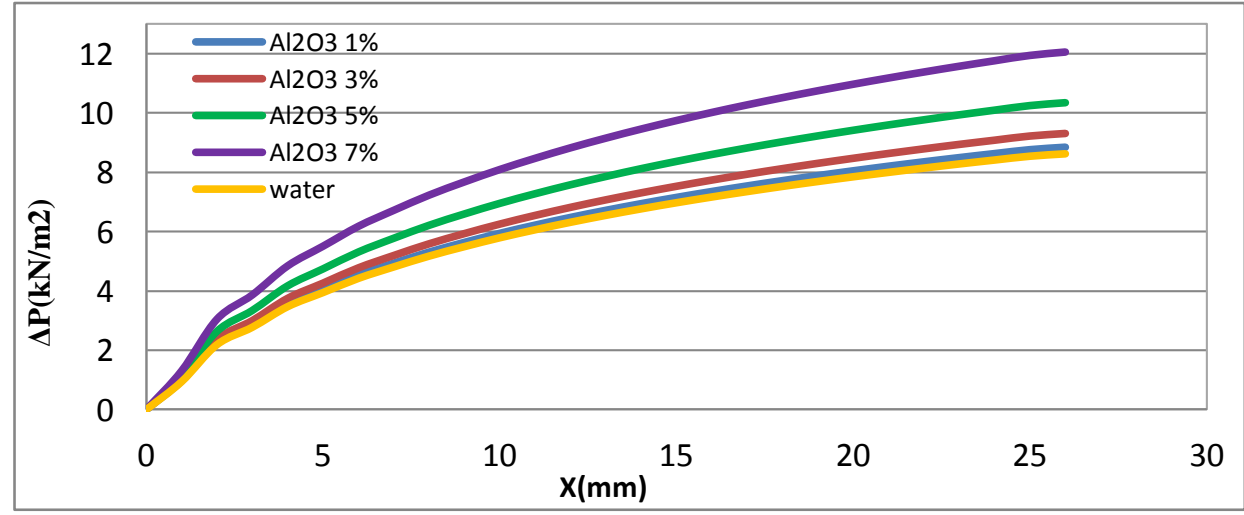

Figure 9: pressure drop along axial distance for $\mathrm{Al}_{2} \mathrm{O}_{3}$-water for channel1 $(\mathrm{Re}=50)$ 


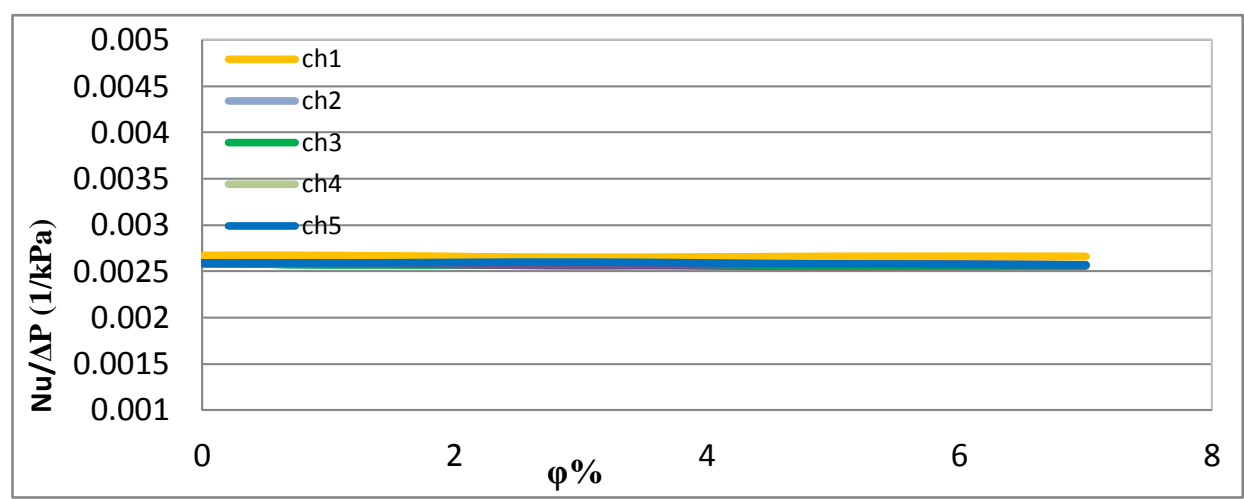

Figure 10: $\mathrm{Nu} / \Delta \mathrm{P}$ variation with volume concentration along five channels using $\mathrm{TiO}_{\text {- }}$-water $(\mathrm{Re}=50)$

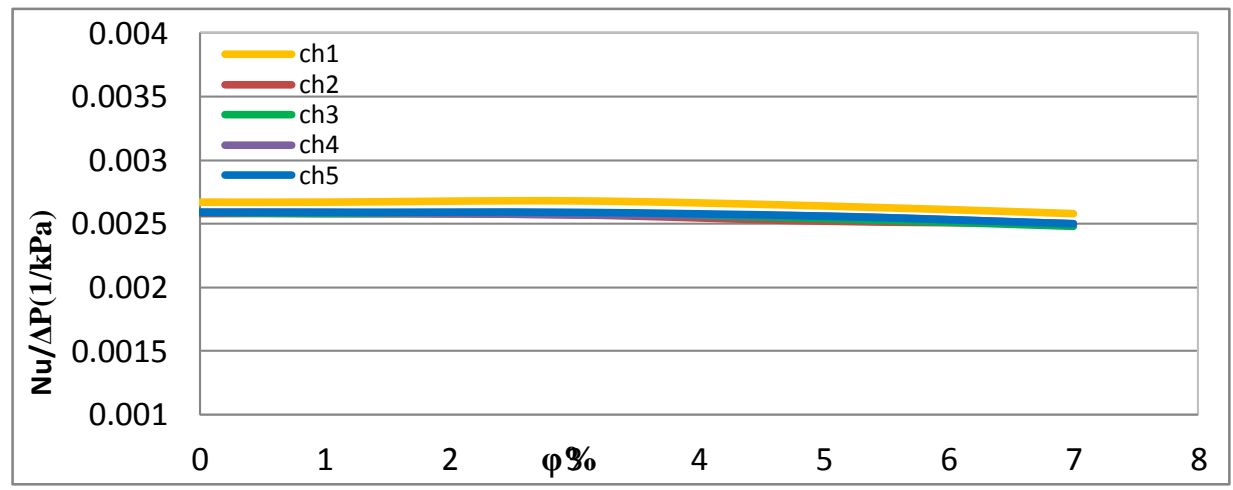

Figure 11: $\mathrm{Nu} / \Delta \mathrm{P}$ variation with nano volume concentration along five channels using $\mathrm{Al}_{2} \mathrm{O}_{3}$-water $(\mathrm{Re}=50)$

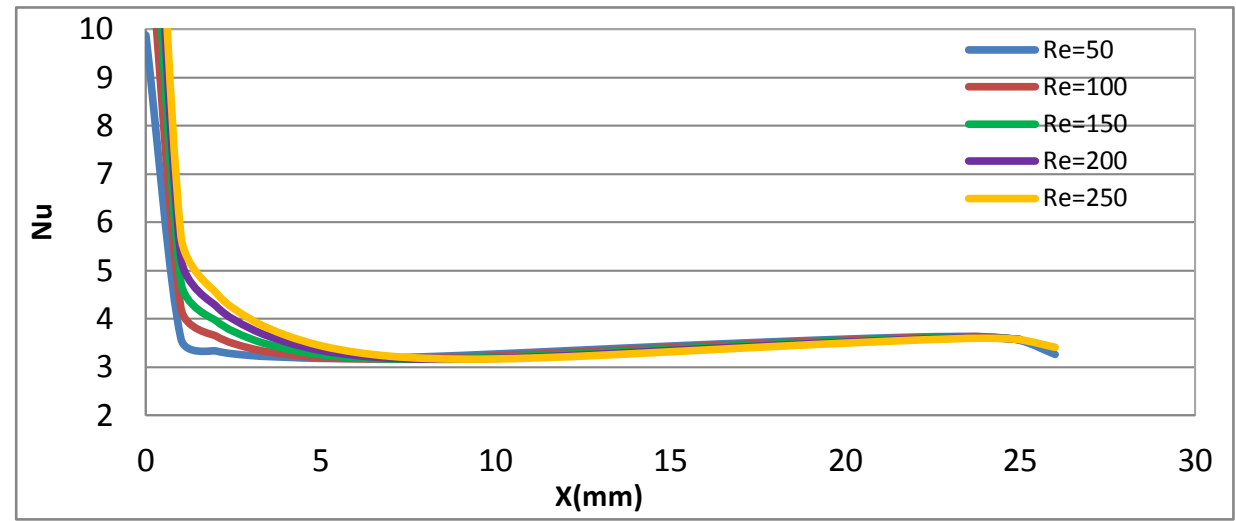

Figure 12: $\mathrm{Nu}$ along axial distance for one channel at different $\mathrm{Re}$

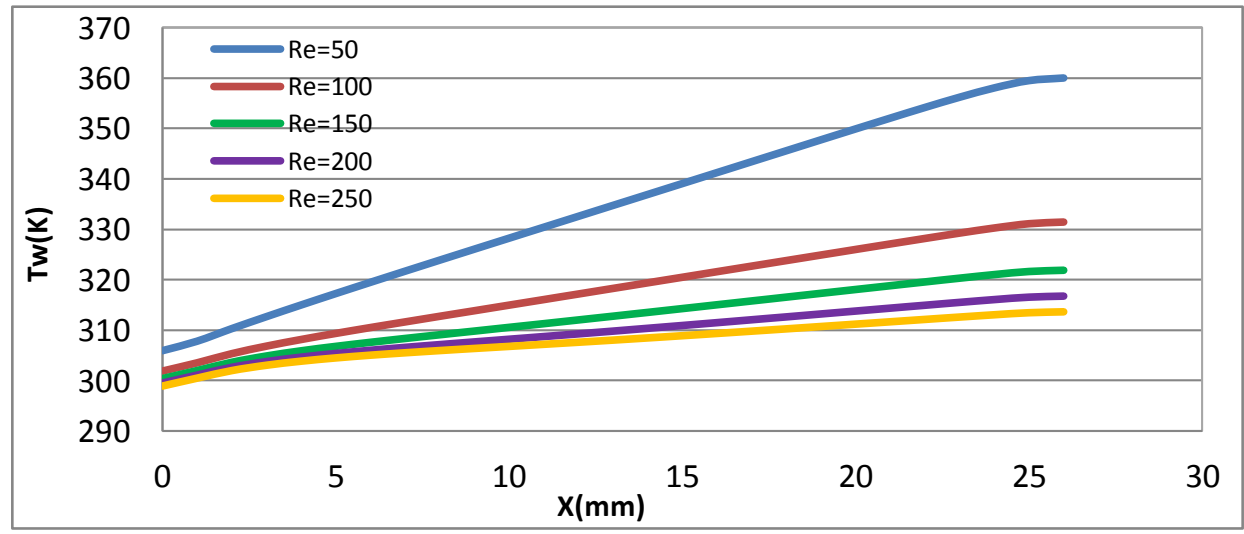

Figure 13: wall temperatures on channel1 at different $\mathrm{Re}$ for $\mathrm{TiO}_{2} 3 \%$ 


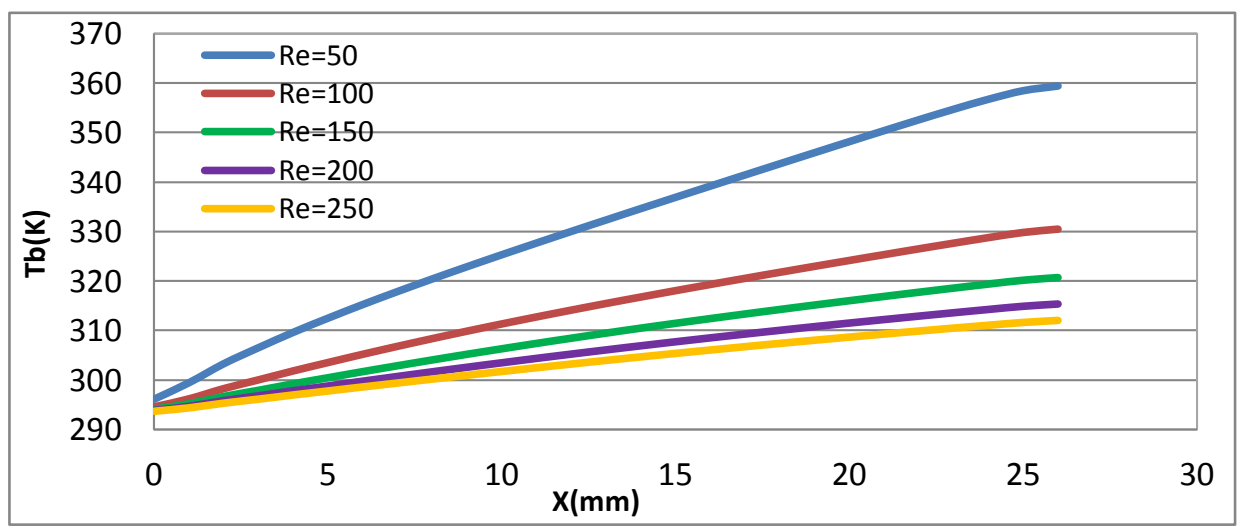

Figure 14: fluid temperature on channel 1 at different $\mathrm{Re}\left(\mathrm{TiO}_{2}=3 \%\right)$

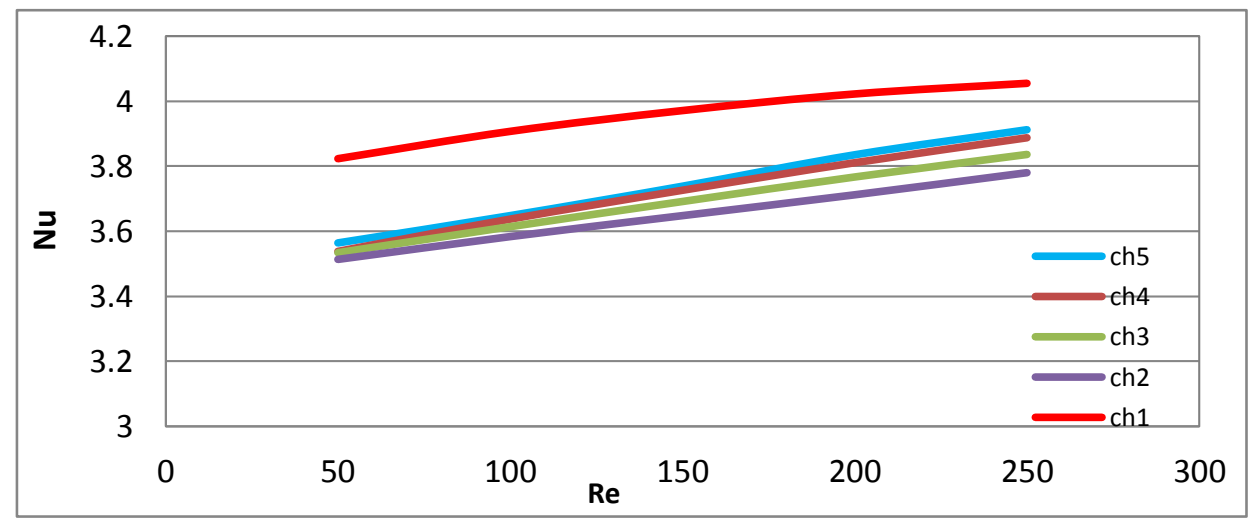

Figure 15: $\mathrm{Nu}$ variation with $\mathrm{Re}$ along five channels $\left(\mathrm{TiO}_{2} 3 \%\right)$

Table III:- the thermal heat sink performance for two fluids at five channels

\begin{tabular}{|c|c|c|c|c|c|}
\hline$\Phi \%$ & \multicolumn{5}{|l|}{$\mathrm{TiO}_{2}$-water } \\
\hline & Ch1 & Ch2 & Ch3 & Ch4 & Ch5 \\
\hline 1 & 1 & 1 & 0.992278 & 1 & 1 \\
\hline 3 & 1.003861 & 0.988417 & 0.992278 & 0.996124 & 0.992509 \\
\hline 5 & 0.996139 & 0.996139 & 0.988417 & 0.988372 & 0.996255 \\
\hline \multirow[t]{3}{*}{7} & 0.992278 & 0.992278 & 0.988417 & 0.992248 & 0.996255 \\
\hline & \multicolumn{5}{|c|}{$\mathrm{Al}_{2} \mathrm{O}_{3}$-water } \\
\hline & Ch1 & Ch2 & Ch3 & Ch4 & Ch5 \\
\hline 1 & 1 & 1 & 0.996139 & 1 & 1 \\
\hline 3 & 1 & 0.992278 & 0.996139 & 0.996124 & 1.003745 \\
\hline 5 & 0.988417 & 0.988417 & 0.980695 & 0.976744 & 0.988764 \\
\hline 7 & 0.965251 & 0.965251 & 0.957529 & 0.968992 & 0.966292 \\
\hline
\end{tabular}

\section{Conclusion:-}

In the current study, the fluid flow and heat transfer through divergence microchannels heat sinks using two nanofluids have been investigated using numerical simulation. The effect of nanofluids type, volume fractions and Reynolds number on Nusslet number, pressure drop and heat sink performance were investigated. The following conclusions were obtained:

1. The Nusselt number of the nanofluids increased with increasing volume fraction of the suspended nanoparticles, and the Reynolds number.

2. The fluid which has high density gave the best value of $\mathrm{Nu}$.

3. The fluid outlet temperature and the temperatures on the upper wall of the heat sink were reduced with increasing of Reynolds. 


\begin{tabular}{|c|c|}
\hline Nomenclature & \\
\hline A Heat transfer area, $\mathrm{m}^{2}$ & $\mathrm{C}_{\mathrm{p}}$ Specific heat at constant pressure, $\mathrm{J} / \mathrm{kg} . \mathrm{K}$ \\
\hline $\begin{array}{l}D_{h} \text { Hydraulic diameter, }=4 A_{f} / P, \mathrm{~m} \\
\mathrm{t} \text { Separating wall thickness, } \mathrm{mm}\end{array}$ & $\begin{array}{l}\mathrm{H}_{\mathrm{ch}} \text { Channel height, } \mu \mathrm{m} \text {. L Channel length, } \mu \mathrm{m} \text {, } \\
\mathrm{K}_{\mathrm{f}} \text { fluid Thermal conductivity, } W / m . K\end{array}$ \\
\hline$N u$ Nusselt number, $=\frac{h D_{h}}{k_{f}}$ & $P, \Delta p$ Pressure, Pressure drop, $N / m^{2}$ \\
\hline$H_{s}$ sink height, $W_{s}$, sink width, $m$ & $R e$, Reynolds number, $=\frac{\rho \mathrm{u} \mathrm{D}_{\mathrm{h}}}{\mu}$ \\
\hline $\begin{array}{l}\mathrm{T}_{\mathrm{f}}, \mathrm{T}_{\mathrm{s}} \text { Temperature of fluid, wall } K \\
\mathrm{~W}_{\mathrm{ch}} \text { Channel width.... mm } \\
\text { Greek Symbols }\end{array}$ & $\begin{array}{lr}u, v, w & \text { Velocity in } x, y, z, \mathrm{~m} / \mathrm{s} \\
x, y, z & \text { Cartesian coordinates }\end{array}$ \\
\hline Dynamic viscosity $\mu$ & Divergence angle $\theta$, Degree \\
\hline Fluid density $\rho$ & $\varphi$ volume fraction of nanofluids \\
\hline
\end{tabular}

\section{References:-}

1. Dharaiya,V.V, Kandlikar. S.G. " Numerical Investigation of Heat Transfer in Rectangular Microchannels Under $\mathrm{H}_{2}$ Boundary Condition During Developing and Fully Developed Laminar Flow". Journal of Heat Transfer. February. Vol. 134. 2012.

2. Fu, B, R. "Liquid-Liquid Mixtures Flow in Microchannels". Transactions of the Canadian Society for Mechanical Engineering, Vol. 37, No. 3, 2013. PP631-641. 2013.

3. Akbarinia. A. Laur, R. Bunse, A. "Developing of laminar fluid flow in rectangular microchannels". The 2nd WSEAS International Conference on Engineering Mechanics, Structures and Engineering Geology. Germany.

4. Hegde. P. G. "Microchannel Heat Sinks For Cooling High Heat Flux electronic Devices-Analysis With Single And Two Phase Flows". Thesis. 2006. University of Sains Malaysia.

5. Ryu. J. H, Choi. D.H, Kim. S.J. "Three-dimensional numerical optimization of a manifold microchannel heat sink". International Journal of Heat and Mass Transfer 46. PP1553-1562. (2003)

6. Sheikhzadeh. G. A, Qomi. M. E, Hajialigol. N, Fattahi. A. "Effect of Al2O-water nanofluid on heat transfer and pressure drop in a three-dimensional microchannel". International Journal of Nano Dimension. Vol.3, No.4, pp281-288. (2013)

7. Tuckerman. D. B and R. F. W.(1981) " High-Performance Heat Sinking for VLSI "Pease. Ieee electron device letters, VOL. EDL-2, NO. 5, MAY 1981.

8. Duangthongsuk. W, Wongwises. S. "Heat transfer enhancement and flow characteristic of $\mathrm{Al}_{2} \mathrm{O}-\mathrm{water}$ nanofluids flowing through a microchannel heat sink". The Second TSME International Conference on Mechanical Engineering. (2011)

9. Manay. E, Sahin B, Yilmaz M, Gelis K. "Thermal Performance Analysis of Nanofluids in Microchannel Heat Sinks". World Academy of Science, Engineering and Technology. Vol.6, pp87-93. (2012)

10. Arjun. K. S, Rakesh. K. "Heat Transfer Enhencement Using Alumina Nanofuid in Circular Micro Channel". Journal of Engineering Science and Technology. Vol. 12, No.1. PP 265-279. (2017)

11. Adham. A. M, Ghazali. N. M, Ahmad. R. "Optimization of Nanofluid-Cooled Microchannel Heat Sink". Thermal Science, Vol. 20, No. 1, pp 109-118. (2016)

12. Ebrahimi. A, Rikhtegar. F, Sabaghan. A, Roohi. E. "Heat transfer and entropy generation in a microchannel with longitudinal vortex generators using nanofluids". Energy 101, pp190-201. (2016)

13. Fedorov. A. G. Viskanta. R. "Three-dimensional conjugate heat transfer in the microchannel heat sink for electronic packaging". International Journal of Heat and Mass Transfer 43. PP.399-415. (2000)

14. Ismaila. M. F, Rashidb. M. A. I, Mahbubb. M. " Numerical Simulation OF Fluid Flow and Heat Transfer in a MEMS-Based Micro Channel Heat Sink. Frontiers in Heat and Mass Transfer (FHMT), 3, 033002. 2012.

15. Noh. N. H. M, Fazeli. A Sidik. N. A. "Numerical Simulation of Nanofluids for Improved Cooling Efficiency in Microchannel Heat Sink". Journal of Advanced Research in Fluid Mechanics and Thermal Sciences. Vol. 4, No. 1, pp 13-23. (2014) 